\title{
Vicarious calibration of EO-1 Hyperion
}

\begin{tabular}{|c|c|}
\hline Journal: & $\begin{array}{l}\text { Journal of Selected Topics in Applied Earth Observations and Remote } \\
\text { Sensing }\end{array}$ \\
\hline Manuscript ID: & JSTARS-2012-00067 \\
\hline Manuscript type: & $\begin{array}{l}\text { The Earth Observing One (EO-1) Satellite Mission: Over a Decade in } \\
\text { Space Special Issue }\end{array}$ \\
\hline $\begin{array}{l}\text { Date Submitted by the } \\
\text { Author: }\end{array}$ & 29-Feb-2012 \\
\hline Complete List of Authors: & $\begin{array}{l}\text { McCorkel, Joel; NASA, Biospheric Sciences } \\
\text { Thome, Kurt; NASA, Biospheric Sciences } \\
\text { Ong, Lawrence; Science Systems and Applications, Inc., NASA/GSFC }\end{array}$ \\
\hline Keywords: & Calibration \\
\hline
\end{tabular}




\title{
Vicarious calibration of EO-1 Hyperion
}

\author{
Joel McCorkel, Kurtis Thome, Lawrence Ong
}

\begin{abstract}
The Hyperion imaging spectrometer on the Earth Observing-1 satellite is the first highspatial resolution imaging spectrometer to routinely acquire science-grade data from orbit. Data gathered with this instrument needs to be quantitative and accurate in order to derive meaningful information about ecosystem properties and processes. Also, comprehensive and long-term ecological studies require these data to be comparable over time, between coexisting sensors and between generations of follow-on sensors. One method to assess the radiometric calibration is the reflectance-based approach, a common technique used for several other earth science sensors covering similar spectral regions. This work presents results of radiometric calibration of Hyperion based on the reflectance-based approach of vicarious calibration implemented by University of Arizona during 20012005. These results show repeatability to the $2 \%$ level and accuracy on the $3-5 \%$ level for spectral regions not affected by strong atmospheric absorption. Knowledge of the stability of the Hyperion calibration from moon observations allows for an average absolute calibration based on the reflectance-based results to be determined and applicable for the lifetime of Hyperion.
\end{abstract}

\section{Introduction}

Over a decade of measurements made by the Hyperion imaging spectrometer has enabled scientists to explore new methods and algorithms of characterizing the earth's surface with high spectral fidelity remote sensing data. Many of these and future techniques use physics-based calculations to extract land-use and land-cover changes, biochemical and biophysical properties of the earth's surface from Hyperion's imagery. For this, and to allow consistency with current and future remote sensing instrumentation, accurate and traceable calibration is required.

There are many techniques to ensure that a sensor's calibration is known and each has its own strengths and weaknesses. Preflight characterization is the most thorough but it is often difficult to create test apparatus that exactly emulate operational conditions and anticipate how the senor may be affected by launch and the space environment (Barnes et 
al, 2001). Many sensors, including Hyperion, have on-board calibrators that provide valuable information about sensor behavior such as detector-to-detector variability and trends in sensor health. However, on-board calibrators will never be able to provide an absolute calibration that is more accurate than the preflight characterization.

Several techniques have been developed to characterize sensors vicariously and independent from prelaunch and on-board calibrators including repeated lunar acquisitions, comparisons to other sensors, and comparisons to ground-based measurements. Distinct advantages of the moon look technique is that the surface of the moon is highly stable and provides a data set with reasonable temporal frequency that will improve over time as the knowledge of the lunar phase effects becomes more accurate and precise. Comparisons with other sensors, also referred to as cross-calibration or inter-comparison, is complex due to variables such as coincident acquisition times, viewing and illumination geometries, and spectral coverage differences. These issues are compounded when transferring calibration knowledge from one sensor to another and this technique can only be as accurate as the sensor's prelaunch characterization. The third method mentioned uses ground-based measurements to predict the sensor's calibration.

Ideally, all of these calibration techniques would be implemented for Hyperion and all would agree within their uncertainties. Unfortunately, it was found that the radiometric response of Hyperion changed significantly between preflight characterization and early on-orbit results in 2001 (Biggar et al, 2003). Subsequent imagery from Hyperion included approximately $10 \%$ and $20 \%$ spectrally flat factors on radiance for the VNIR and SWIR focal planes, respectively. This work provides a more 
accurate and spectrally dependent radiometric characterization for Hyperion using a combination of vicarious techniques. First, the reflectance-based approach is used to find the absolute radiometric calibration and, second, historical lunar acquisitions are used to show that it is valid throughout most of the sensor's lifetime.

The next section describes the reflectance-based approach including test sites employed, measurement techniques, prediction of at-sensor radiance and formulation of results followed by discussion of lunar acquisitions and the long-term stability of Hyperion. The third section presents results based on field measurements collected 20012005 with supporting moon-based studies. The reflectance-based and moon-based results are used in combination to provide an absolute radiometric calibration and show that it is valid 2001-present. The final section discusses limitations of results presented here regarding the spatial channels for which this work is valid and provides direction for future work that extends these results to the entire focal plane.

\section{Reflectance-based approach}

One method of vicarious validation of at-sensor radiance is the reflectance-based approach, successfully implemented by several research groups and applied to dozens of Earth-observing sensors (Vane et al, 1993; Thome, 2001; Thome, 2004a,b; Arai et al, 2005). This method relies on in situ measurements that characterize surface reflectance and atmospheric properties of a test site to provide input to a radiative transfer model to predict at-sensor radiance. These values are then compared with corresponding 
measurements of the airborne or spaced-based sensor. The remainder of this section describes the approach for each of these aspects.

\section{A. Test site}

Desirable test site properties for the reflectance-based approach as well as other calibration methods include high-reflectance, spatially uniform over large areas, and high in elevation (Scott et al., 1996). The overarching idea behind these characteristics is to get closer to the ideal case of zero atmosphere by maximizing the signal due to directly reflected solar irradiance. A bright test site with a reflectance with 0.3 or greater maximizes signal component due to directly reflected solar irradiance for most spectral regions. Spatially uniform sites reduce concerns such as registration and adjacency effects seen in some radiative transfer studies when the surface reflectance surrounding the test site is different than that of the test site. Test sites at high elevations have less atmospheric aerosols and errors associated with their characterization have less effect. Other desirable test site characteristics are near lambertian reflectance properties and temporal stability. A lambertian site will reduce effects due to solar and view geometries. A temporally stable site allows consistency between day-to-day, season-to-season, and year-to-year studies. Lastly, logistics and cost of traveling to a test site with an assortment of personnel and instrumentation control the locality of the test site. The Railroad Valley Playa (RVPN), a large desert basin in Nevada, satisfactorily satisfies the criteria described above and is selected for this work. 
This work includes two rectangular test site layouts used at RVPN: a $90 \times 240$ meter site with its long edge in Hyperion's cross-track direction and a $120 \times 480$ meter site with its short edge in Hyperion's cross-track direction. Considering that Hyperion has a 30-meter ground sample distance, these sites represent 8 and 4 spatial pixels in Hyperion's cross-track, respectively. Earlier data sets use the site orientation that cover more of the cross-track pixels due to a focused effort to characterize EO-1 sensors during its first year of operation. Later data sets use the $120 \times 480$ meter site optimized for a Landsat-type sensor (Thome, 2001).

\section{B. Reflectance characterization}

In most spectral regions in the solar-reflective spectrum, the dominant signal component is directly reflected solar irradiance and therefore surface reflectance characterization is the most important aspect of the reflectance-based approach. The following method characterizes the biconical reflectance factor of the test site for the geometry given by the solar position and the view of ground-based instrument. Biconical reflectance is the measured quantity, however this will be approximated as the bidirectional reflectance factor (BRF) in this work due to the small angular subtense of source and sensor. Also, the solar geometry changes throughout the period of the measurement meaning the ground-based BRF measurement is not exactly the same as the BRF conditions at the time that the sensor acquired the test site. Near-Lambertian test sites and measuring the surface reflectance close in time to the sensor acquisition reduces errors associated with geometry effects. 
The $90 \times 240$ and $120 \times 480$ meter sites are sampled over evenly spaced transects. For a reasonably uniform site transect spacing is selected to be the ground-sample distance of the imager; more frequent spacing may increase sampling time too much and less frequent spacing may not provide enough statistical sampling for each detector.

Measurements obtained by a field-portable spectroradiometer are used to calculate the reflectance of the test site. These measurements consist of a 16-bit output at 1-nm spectral intervals covering a spectral range of $350-2500 \mathrm{~nm}$. The $1-\mathrm{nm}$ interval data is interpolated from raw measurements of $1.4 \mathrm{~nm}$ sampling intervals with $3-\mathrm{nm}$ resolution from 350-1000 nm and 2-nm sampling intervals with $10 \mathrm{~nm}$ resolution from 1000-2500 nm. Light is gathered by a fiber optic bundle that feeds the entrance slit of the spectroradiometer. The 25-degree field-of-view of the fiber optic bundle is converted to 8 degrees with a foreoptic giving the instrument a footprint of about $20 \mathrm{~cm}$ when held at about $1.5 \mathrm{~m}$ above the ground. The instrument is carried by an operator along each of the transects mentioned above. A reference measurement is taken over a well-characterized diffuser before and after each transect. $\operatorname{BRF}\left(0^{\circ}, \theta\right)$ of the diffuser traceable to standards defined by National Institute of Standards and Technology (NIST) is characterized in five degree increments of $\theta$ in the range of possible solar geometries over the $350-2500 \mathrm{~nm}$ spectral region in 22 narrow spectral bands (Biggar et al, 1988). Using reference measurements surrounding each of the test site transect measurements and their associated timestamps, automated processing techniques calculate a reference BRF for each measurement along the transect to compensate for varying solar illumination geometries throughout the duration of measurements. The calculated reference BRF values are transferred to each of the transect measurements providing NIST-traceable 
BRF of the test site. The mean of these spectral BRF values are used to constrain the radiative transfer model.

\title{
D. Atmospheric characterization
}

\begin{abstract}
Although directly reflected radiance is the dominant part of the at-sensor signal for the bright surface and high elevation of RVPN, atmospheric effects must be considered to accurately predict at-sensor radiance. Molecular and aerosol components of the atmosphere attenuate and scatter light with strong spectral dependencies. Characterizing these effects relies on atmospheric temperature and pressure measurements and solar extinction measurements from a ten spectral channel solar radiometer. The effects of the molecular component are characterized using the Rayleigh approximation using atmospheric temperature and pressure data (Penndorf 1957, Teillet 1990). Next, effects of the aerosol component and absorption features are characterized using atmospheric optical depths retrieved from solar radiometer measurements that are relatively calibrated using the Langley method (Biggar, 1990; Gellman et al., 1991). Columnar ozone amount is extracted from a freely available database of total ozone derived from measurements by either Total Ozone Mapping Spectrometer (TOMS) or Ozone Monitoring Instrument (OMI) depending on the date (McPeters et al., 1998; Veefkind et al., 2006). A power law is used to describe the aerosol size distribution and to derive at values for aerosol optical depth at 1-nm intervals over the 350-2500 nm spectral range (Ångström, 1929). Lastly, columnar water vapor is derived from the solar radiometer measurements using a modified Langley approach (Reagan et al., 1992).
\end{abstract}




\section{E. Radiative transfer}

The surface and atmospheric properties found above serve to constrain the radiative transfer code that predicts at-sensor radiance for a variety of remote sensing instrumentation. The code used in this work is MODTRAN4 (Berk et al., 1987; Berk et al., 1998). The model assumes a solar spectrum, the Chance-Kuruzc curve for this work, and simulates its path through the atmosphere to the ground, its interaction with the ground, and finally its path towards the sensor. The bottom layer is Earth's surface and is modeled to be opaque and characterized by the input reflectance spectrum. Transmittance calculations are based on band models of molecular line absorption, continuous molecular absorption, and extinction coefficients of aerosols.

Geometries of the sensor and sun at the time the sensor measures the test site are also included in the input. The mid-latitude summer atmospheric model in MODTRAN is used in this work which defines atmospheric profiles for $\mathrm{H}_{2} \mathrm{O}, \mathrm{O}_{3}, \mathrm{~N}_{2} \mathrm{O}, \mathrm{CO}$, and $\mathrm{CH}_{4}$ that are proper for the altitude, pressure and column ozone provided to the model. The $\mathrm{CO}_{2}$ mixing ratio is set to $365 \mathrm{ppm}$. Aerosol optical depth at $550 \mathrm{~nm}$ and Ångström parameter is provided to define aerosol spectral extinction. The size distribution derived from the solar radiometer measurements using power law assumption is used to Mie scattering spectral phase functions.

The model is set to assume a lambertian surface with spectral reflectance of the test site that is measured close in time to sensor acquisition. This assumption is valid if geometries of ground-based measurements match those of the remote sensing instrument 
(i.e. the foreoptic of the field-portable spectroradiometer is pointing at the test site in the same direction as the remote sensing instrument). The model assumes that the entire surface has the same reflectance, which may cause inaccurate results if the area surrounding the test site has significantly different spectral reflectance due to groundatmosphere interaction. Due to the large area of RVPN (approximately $15 \times 20 \mathrm{~km}$ ) and its typical low aerosol loading, the atmospheric point-spread function drops substantially outside of the test sites used in this work.

The output of MODTRAN provides at-sensor radiance at 1-nm intervals with slit functions of 2-nm full-width at half maximum. These data are band-averaged with the appropriate relative spectral responses of Hyperion.

\section{F. Determination of sensor-reported radiance}

At-sensor radiance calculated using surface reflectance characterization, derived atmospheric properties, and solar and view geometries is compared with that measured by Hyperion therefore providing validation independent of laboratory- and onboardbased characterizations. The radiance values representing the test site reported by the sensor are determined by extracting the pixel values that represent the test site. To assist in finding the test site in the imagery blue-colored tarpaulins are deployed on the southwest corner of the site. Each spatial column of Hyperion has slightly different spectral characteristics than adjacent columns since it is a pushbroom spectrometer. This means that each pixel of Hyperion has a unique spectral response function, the case for all imaging spectrometers. Prelaunch characterization showed that Hyperion's spectral 
response functions are well represented with gaussian functions and therefore only center wavelength and full-width at half-maximum values are needed to fully define the spectral response of each pixel. Variation in spectral response function varies slowly such that there is small change over the extent of a few pixels but larger differences are seen from different locations on the focal plane. Each instance of reflectance-based calibration covers a different group of spatial columns of Hyperion. Spatial column information is recorded when extracting sensor-reported radiance from Hyperion imagery to accurately account for varying spectral properties across the spatial swath.

\section{Hyperion lunar acquisitions and comparison to ROLO}

The moon is a convenient calibration source for remote sensing systems because it meets the ideal case of an atmosphere-free surface and has a temporally-stable surface, that is reasonably bright, and illuminated with the same solar source as the earth (Kieffer and Wildley, 1996). Research groups have measured the moon over time and over many spectral channels (Kieffer and Stone, 2005). This work compares the calibration of Hyperion to that of the U.S. Geological Survey Robotic Lunar Observatory (ROLO) model (Stone et al., 2003). Inputs to the ROLO model include moon disk-integrated lunar spectral irradiance, time of observation, position of spacecraft, and size of lunar images in 
the along-track direction. The precision of the ROLO model allow instruments to track changes at the $0.1 \%$ level (Stone and Kieffer, 2004; Keiffer and Stone, 2005).

EO-1 typically collects Hyperion full lunar disk images every two months to supplement trending of the instrument's performance. These are conducted when the spacecraft is in the earth's shadow and when the moon phase angle with respect to the earth of about 7.5 degrees. The data collected are radiometrically corrected and the total irradiances of the moon for each band are calculated from these Level-1R images. The ROLO model is used as a basis for normalizing the measured irradiance to account for the effects of lunar nutation, libration and variances of the sun-moon and moonspacecraft ranges.

\section{Results}

The reflectance-based approach of vicarious absolute calibration was successfully implemented nine times for Hyperion using the Railroad Valley Playa test site in Nevada. These results were obtained over the 2001-2005 period while the EO-1 spacecraft shared a similar orbit with Landsat 7 making ground validations efforts convenient by sharing data sets with multiple satellite sensors. After 2005 the orbit of EO-1 changed, limited resources prevented exclusive campaigns for the sensors of EO-1. Fortunately, EO-1 has routinely made measurements of the moon beginning shortly after its launch. This section presents results from the reflectance-based approach and lunar acquisitions that when combined give a radiometric characterization valid for nearly the entire lifetime of Hyperion. 
Each calibration data set Hyperion acquired the RVPN test sites on slightly different portions of the Hyperion focal plane. A summary of focal plane coverage is shown in Figure 1a where the horizontal axis is Hyperion's spatial column and vertical axis is the date of the collection. Recall that each pixel of Hyperion has a unique spectral response function defined by a band center and bandwidth of a gaussian curve. The band center wavelength is slowly varying across the focal plane for a given spectral channel and the variation is nearly negligible for a four-to-eight pixel-sized test site. Figure $1 b$ shows the maximum band center change across the field of a test site for the VNIR and SWIR focal planes. The band center changes from one data set to another is more significant and as much as $0.5 \mathrm{~nm}$ between the extremes as shown in Figure 1c. Therefore, the approach used to band average predicted at-sensor radiance is to use the average band center and bandwidth for each data set.

The dates and times of each Hyperion acquisition used in this work are listed in Table I. The corresponding surface reflectance measurement time, test site layout, solar and sensor geometries, and atmospheric parameters are listed for each overpass. The surface reflectance of the test site was typically measured over a 30-40 minute period during which the solar zenith has a nominal change of about five degrees. Most of the data sets have a high solar zenith angle in the range of 25-30 degrees except for two winter data sets having solar zenith angle of 45 and 50 degrees. The reflectance-based method is insensitive to these differences because surface reflectance is characterized with the ground-based instrumentation in nearly the same view and illumination geometry as Hyperion. 
The solid line in Figure 2 shows surface spectral reflectance of the $120 \times 480 \mathrm{~m}$ site at RVPN as measured on 5 March 2005 and the dashed line shows the percent standard deviation of the mean. The reflectance curve is typical of RVPN and very similar to the other data sets. The standard deviation represents a combination of measurement noise and test site variability. The variability shown for 5 March 2005 of about $5 \%$ in most spectral regions is the highest of the ten data sets used in this work and most are in the range of $2-4 \%$. The peaks in standard deviation near 1400 and $1800 \mathrm{~nm}$ are due to low signal levels caused absorption due to water vapor. The $2300-2500 \mathrm{~nm}$ spectral region also experiences significant variability due to decreasing signal level and increasing instrument noise.

The measured surface reflectance and corresponding atmospheric parameters are used to constrain the radiative transfer code to predict at-sensor radiance which has an output with higher spectral resolution than the Hyperion bands. The spectral radiance curve from the radiative transfer code is band averaged with the appropriate spectral response functions that depend on the spatial location on the focal plane where the test site is imaged. The results are presented as percent disagreement between the at-sensor radiance prediction and radiance reported by the current calibration of Hyperion.

$$
\% \text { difference }=\frac{L_{\text {predicted, } \lambda}-L_{\text {Hyperion }, \lambda}}{L_{\text {predicted }, \lambda}}
$$

where $\mathrm{L}_{\text {predicted, } \lambda}$ and $\mathrm{L}_{\text {Hyperion, } \lambda}$ are the spectral radiance values from the reflectance-based approach and Hyperion, respectively. The averaged \% difference results from the nine field campaigns are shown in Figure 3. Spectral regions of large deviation from zero, such as 940, 1130, 1350 and $2400 \mathrm{~nm}$, are affected by strong water vapor absorption. A combination of lower signal for both Hyperion and the ground-based spectrometer 
coupled with high sensitivity to atmospheric characterization in these spectral regions leads to unreliable results. The remainder of the data in Figure 3 shows agreement between Hyperion and reflectance-based results to within $-5 \%$ and $+10 \%$. A convenient way to assess the consistency of these results is to find the standard deviation of the mean as shown in Figure 4. Excluding the high variability of the previously mentioned spectral regions affected by water vapor absorption, the consistency for the reflectance-based method is on the $2 \%$ level. The band-to-band consistency of the standard deviation indicates that band-to-band variability in the percent differences are real effects caused by the calibration of Hyperion. The implication of these results is that a smoothly varying spectral radiance would display band-to-band variations on the order of 5-10\% simply because of the radiometric calibration of the system.

The results shown here for Hyperion compare favorably in standard deviation to those derived for other sensors (Thome, 2001; Thome et al., 2003, McCorkel et al., 2006). Such favorable comparisons give confidence in the results for Hyperion. Additionally, each of the nine dates shown also included calibration attempts for other sensors using the ground data collected for Hyperion or using data sets collected near in time and location for other sensors. The results for the other sensors are consistent with long-term trends for those instruments (such as Landsat-5 Thematic Mapper and Landsat 7 Enhanced Thematic Mapper Plus). The internal consistency of the reflectance-based results with other dates and imagers gives good confidence in the average percent difference shown for Hyperion.

Reflectance-based results for Hyperion cover the 2001-2005 period, concurrent with less than half of Hyperion's lifetime, means that they can not provide the exclusive 
calibration. This work uses reference to the moon to show that the reflectance-based results presented above remain valid through the mission. The black lines in Figure 5 show the changes in Hyperion response over the past 11 years as deduced by the ROLO normalized measurements. The comparison to ROLO is shown for six channels, three for the each of Hyperion's focal planes. The red lines in Figure 5 are linear best fits to ROLO-based results and the associated annual degradation rates are shown in Table II. All channels presented here show $0.1 \%$ /year or less rate of change except for channel 11 with band center at $457 \mathrm{~nm}$.

The blue circles in Figure 5 show the reflectance-based results for the same spectral channels. The average values with associated percent standard deviation and rates of change are shown in Table II. There is limited confidence in these degradation rates due to the relatively small number of data points and $2 \%$ relative uncertainty. The primary differences in these data sets other than the temporal coverage discussed above are significant absolute differences and larger scatter in the reflectance-based results. The amount of variability in the reflectance-based data set is expected due primarily to uncertainties in the reflectance retrieval. The absolute uncertainty of the reflectancebased method has been shown to be $<3 \%$ for the spectral bands shown here (Thome et al., 2005). The absolute uncertainty in the knowledge of the lunar calibration is 5-10\% (Stone and Kieffer, 2006). Thus, the results shown in the figures technically overlap in an absolute sense.

The true power of the lunar results shown are that they cover a much longer time period than the reflectance-based results and the better precision of the lunar data allows for greater confidence in the trend of the calibration of Hyperion. The results for the 457- 
$\mathrm{nm}$ band are still being evaluated to determine if the small change in response over the 10 years of Hyperion operation is real. Results for the other bands show very good stability for the Hyperion sensor for the lifetime of the instrument. Knowledge of the stability of the Hyperion calibration allows for an average absolute calibration based on the reflectance-based results to be determined and applicable for the lifetime of Hyperion.

\section{Conclusion}

Nine vicarious calibration campaigns consisting of ground-based reflectance and atmospheric measurements, known as the reflectance-based approach, during 2001-2005 were held for the Hyperion imaging spectrometer. Disagreement between spectral radiance predicted with the reflectance-based approach and that measured by Hyperion ranges $-5-10 \%$ depending on spectral region. The variability of these results are on the $2 \%$ level based on the standard deviation of the nine data sets for most spectral channels of Hyperion.

The absolute calibration of the reflectance-based approach is complemented by the more frequent, continuous, and precise characterization provided by lunar acquisitions tied to the ROLO model. Lunar images were acquired at least every two months and the irradiance from the moon is calculated and compared with that calculated from the ROLO model. ROLO-based results have about one quarter of the variability of 
the reflectance-based calibration data set. The stability shown with the lunar data set gives confidence that the absolute calibration of the reflectance-based approach is valid throughout the lifetime of the sensor. Such results should be used to improve the band-toband calibration of the Hyperion sensor to remove effects that cause spectral variability in retrieved surface reflectance.

Such a band-to-band radiometric calibration is not trivial due to the variation in spectral bandpass and center wavelength across the Hyperion swath. The work shown here relies sampling a relatively small portion of Hyperion's spatial swath due to the focal plane location where the RVPN was typically imaged. Therefore these results rely on the quality of the flat field knowledge of the sensor and future work with large and more uniform and stable test sites will increase confidence and should allow a band-toband radiometric calibration of Hyperion. Improved understanding of the absolute radiometric calibration of each Hyperion band will greatly improve the utility of Hyperion data for many applications. As an example, the calibration found here can be used to better characterize the reflectance curve of remote desert test sites that are not accessible for groundwork and these test sites will be used to improve the intercalibration understanding of a wide range of sensors. 


\section{REFERENCES}

Ångström, A., "On the atmospheric transmission of sun radiation and on dust in the air," Geografiska Annaler, Vol. 11, pp. 156-166, 1929.

Arai, K., Tonooka, H., "Radiometric performance evaluation of ASTER VNIR, SWIR, and TIR," IEEE Transactions of Geoscience and Remote Sensing 43(12), 2725-2732 (2005).

Barnes, R. A., R. E. Eplee, Jr., G. M. Schmidt, F. S. Patt, and C. R. McClain, "Calibration of SeaWiFS. I. Direct Techniques," Applied Optics, 40, pp. 6682-6700, 2001.

Berk, A., L.S. Bernstein, and D.C. Robertson, "MODTRAN: A Moderate Resolution Model for LOWTRAN," Air Force Geophysics Laboratory, Air Force Systems Command, Hanscom AFB, Massachusetts, 1987.

Berk, A., L.S. Bernstein, G.P. Anderson, P.K. Acharya, D.C. Robertson, J.H. Chetwynd, S.M. Adler-Golden, "MODTRAN cloud and multiple scattering upgrade with application to AVIRIS," Remote Sensing of Environment 65(3), 367-375 (1998).

Biggar, S.F., Labed, J. F., Santer, R. P., Slater, P. N., Jackson, R. D., and Moran, M. S., "Laboratory calibration of field reflectance panels," Proc. SPIE 924, 232-240 (1988).

Biggar, S.F., "Improved evaluation of optical depth components from Langley plot data," Remote Sensing of Environment, Vol. 32, No. 2-3, pp. 91-101, 1990.

Biggar, S. F., K. J. Thome, W. T. Wisniewski, "Vicarious radiometric calibration of EO1 sensors by reference to high-reflectance ground targets," IEEE Trans. On Geosciences and Remote Sensing, 41, pp. 1174-1179, 2003.

Gellman, D. I., Biggar, S. F., Slater, P. N., \& Bruegge, C. J. (1991). Calibrated intercepts for solar radiometers used in remote sensor calibration. Proceedings of SPIE, 1493, 175180.

Kieffer, H.H., R.L. Wildey, "Establishing the Moon as a Spectral Radiance Standard", J. Atmospheric and Oceanic Technology 13, 2, 360-375 (1996)

Kieffer, H.H., T.C. Stone, "The Spectral Irradiance of the Moon", Astronom. J. 129, 2887-2901 (2005)

McCorkel, J.T., K.T. Thome, S.F. Biggar, M.J. Kuester, "Radiometric Calibration of Advanced Land Imager using reflectance-based results between 2001 and 2005," Proceedings of SPIE, Vol. 6296, 2006. 
McPeters, R. D., Bhartia, P. K., Krueger, A. J., Herman, J. R., Wellemeyer, C. G., Seftor, C. J., Jaross, G., Torres, O., Moy, L., Labow, G., Byerly, W., Taylor, S. L., Swissler, T., \& Cebula Raytheon, R. P. (1998). Earth probe total ozone mapping spectrometer (TOMS) data product user's guide (NASA Technical Publication, 1998-206895). National Aeronautics and Space Administration. Washington, DC, USA.

Penndorf, R., "Tables of the Refractive Index for Standard Air and the Rayleigh Scattering Coefficient for the Spectral Region between 0.2 and $20.0 \mu$ and Their Application to Atmospheric Optics," Journal of the Optical Society of America, 47 (2), 1957.

Reagan, J.A. K.J. Thome, B.M. Herman, “A simple instrument and technique for measuring columnar water vapor via near-IR differential solar transmission measurements," IEEE Trans. Geosci. Rem. Sens., Vol. 30, No. 4, pp. 825-831, 1992.

Scott, K. P., Thome, K. J., Brownlee, M. R., "Evaluation of the Railroad Valley playa for use in vicarious calibration," Proc. SPIE 2818, 158-166 (1996).

Stone, T. C., H. H. Kieffer, and K. J. Becker, "Modeling the Radiance of the Moon for On-orbit Calibration", Proc. SPIE 5151, 463-470 (2003)

Stone, T.C., H.H. Kieffer, "Assessment of Uncertainty in ROLO Lunar Irradiance for Onorbit Calibration", Proc. SPIE 5542, 300-310 (2004)

Stone, T.C., H. H. Kieffer, "Use of the Moon to support onorbit sensor calibration for climate change measurements," Proc. SPIE 6296, 62960Y (2006)

Teillet, P.M., "Rayleigh optical depth comparisons from various sources," Applied Optics, 29 (13), 1897-1900, 1990.

Thome, K.J., "Absolute radiometric calibration of Landsat 7 ETM+ using the reflectancebased method," Remote Sensing of Environment, Vol. 78, No. 1, pp. 27-38, 2001.

Thome, K.J., E.E. Whittington, and N. Smith, "Radiometric calibration of MODIS with reference to Landsat-7 ETM+," Proceedings of SPIE, Vol. 4483, pp. 203-210, 2003.

Thome, K., S. Biggar, and H. J. Choi, "Vicarious calibration of Terra ASTER, MISR, and MODIS,” Proc. SPIE Conf. \#5542, pp. 290-299, Denver, Colo., 2004 a.

Thome, K. J., Helder, D. L., Aaron, D., Dewald, J. D., "Landsat-5 TM and Landsat-7 ETM+ Absolute Radiometric Calibration Using the Reflectance-Based Method," IEEE Transactions of Geoscience and Remote Sensing 42(12), 2777-2785, 2004b.

Thome, K., C. Cattrell, J. D’Amico, J. Geis, "Ground-reference calibration results for Landsat 7 ETM+," Proceedings of SPIE, Vol. 5882, 2005. 
Vane, G., Green, R. O., Chrien, T. G., Enmark, H. T., Hansen, E. G., Porter, W. M., "The Airborne Visible/Infrared Imaging Spectrometer (AVIRIS)," Remote Sensing of Environment 44, 127-143 (1993).

Veefkind, J. P., de Haan, J. F., Brinksma, E. J., Kroon, M., Levelt, P. F., “Total ozone from the ozone monitoring instrument (OMI) using the DOAS technique," IEEE Transactions of Geoscience and Remote Sensing 44(5), 1239- 1244 (2006). 

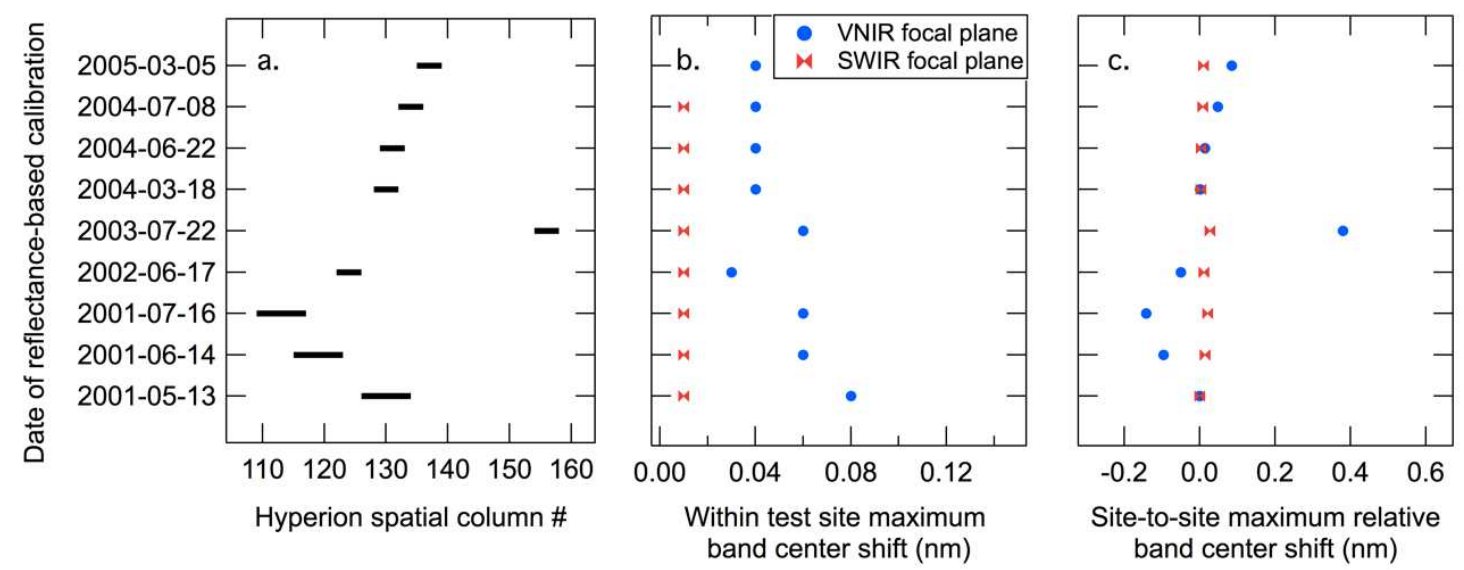

Fig. 1. Spatial and spectral attributes for each calibration data point including a) Hyperion spatial columns covered by RVPN test site for each data set, b) maximum spectral offset of band center values within data sets, and c) maximum spectral offset of band center values amongst data sets relative to the first.

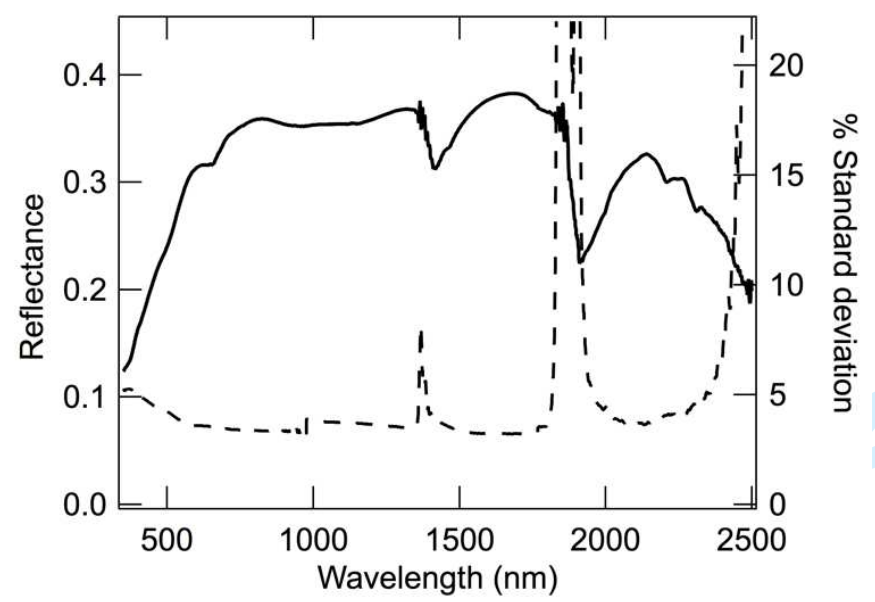

Fig. 2. Spectral reflectance of RVPN measured on 5 March 2005. 


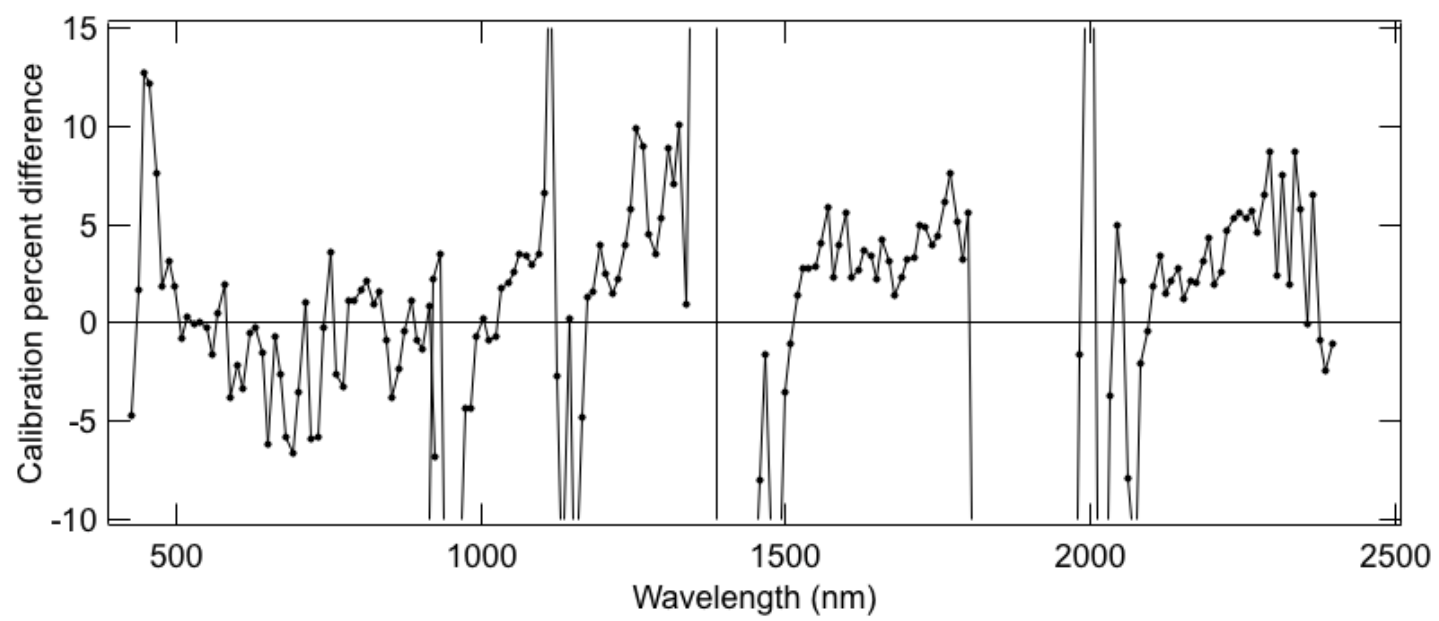

Fig. 3. Mean of nine data sets in the form of percent disagreement between at-sensor radiance prediction and the current calibration of Hyperion.

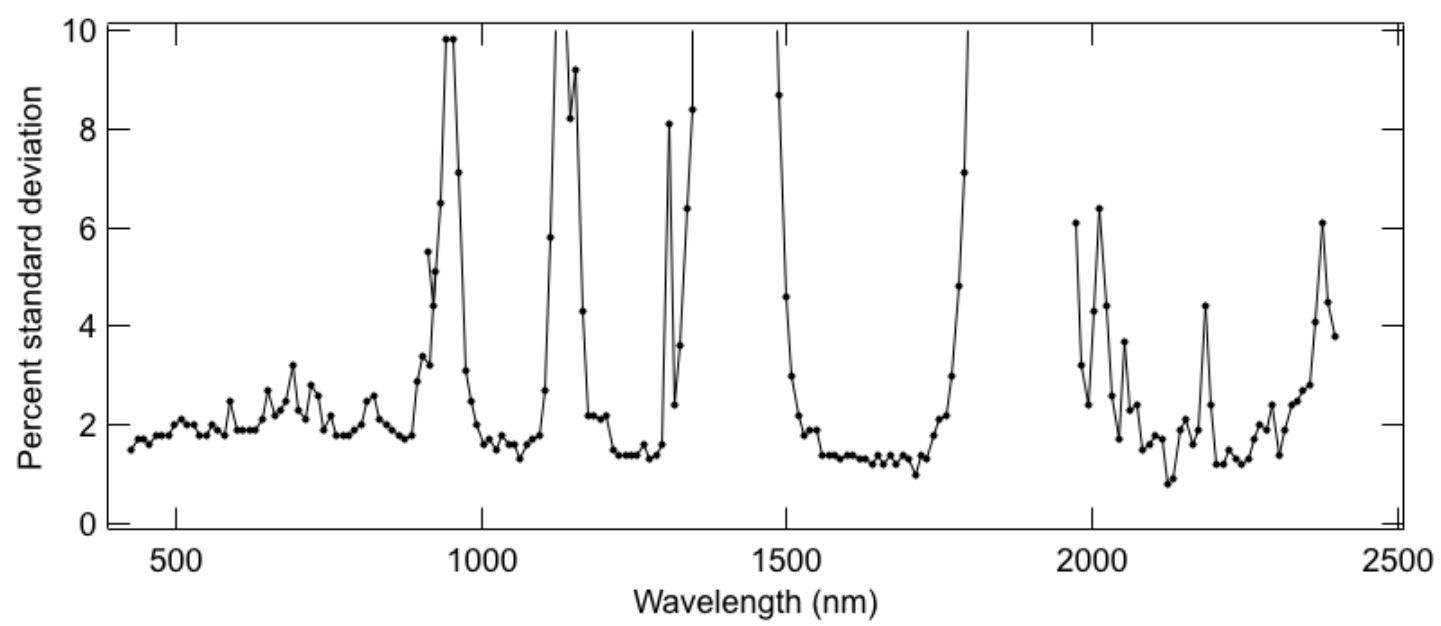

Fig. 4. Percent standard deviation of the mean disagreement between at-sensor radiance prediction and the current calibration of Hyperion. 

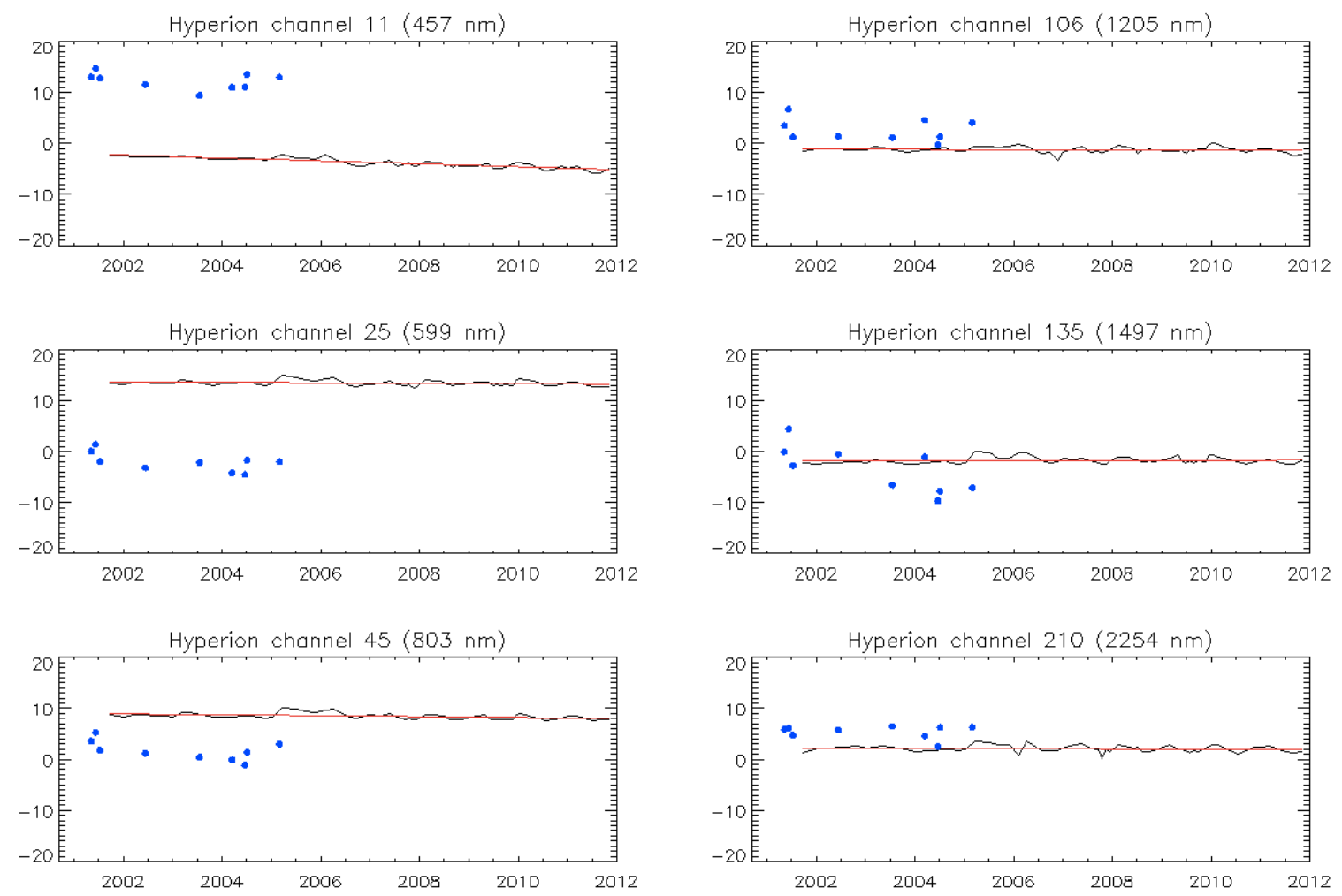

Fig. 5. Hyperion percent difference from the ROLO model and reflectance-based results for three channels each of Hyperion's focal planes.

Table I. Summary of measurement data for the nine Hyperion acquisitions of RVPN with coincident ground collections.

\begin{tabular}{|c|c|c|c|c|c|c|c|c|c|}
\hline Acquisition date & $\begin{array}{r}13 \text { May } \\
2001 \\
\end{array}$ & $\begin{array}{r}14 \text { June } \\
2001 \\
\end{array}$ & $\begin{array}{r}16 \text { July } \\
2001 \\
\end{array}$ & $\begin{array}{r}17 \text { June } \\
2002 \\
\end{array}$ & $\begin{array}{r}22 \text { July } \\
2003 \\
\end{array}$ & $\begin{array}{r}18 \text { March } \\
2004 \\
\end{array}$ & $\begin{array}{r}22 \text { June } \\
2004 \\
\end{array}$ & $\begin{array}{r}8 \text { July } \\
2004 \\
\end{array}$ & $\begin{array}{r}5 \text { March } \\
2005 \\
\end{array}$ \\
\hline Acquisition time (UTC) & $18: 12: 04$ & $18: 11: 40$ & $18: 11: 24$ & $18: 10: 34$ & $18: 10: 37$ & $18: 11: 20$ & $18: 11: 10$ & 18.10:59 & $18: 11: 50$ \\
\hline Surface refl time (UTC) & $\begin{array}{r}18: 13- \\
18: 42\end{array}$ & $\begin{array}{r}17: 50- \\
18: 22\end{array}$ & $\begin{array}{r}17: 40- \\
18: 23\end{array}$ & $\begin{array}{r}17: 33- \\
18: 10\end{array}$ & $\begin{array}{r}17: 46- \\
17: 53\end{array}$ & $\begin{array}{r}17: 45- \\
18: 22\end{array}$ & $\begin{array}{r}17: 37- \\
18: 15\end{array}$ & $\begin{array}{r}17: 35- \\
18: 11\end{array}$ & $\begin{array}{r}17: 36- \\
18: 14\end{array}$ \\
\hline Solar zenith range & $27.2-23.4$ & $28.3-22.8$ & $32.5-25.1$ & $31.4-24.9$ & $32.1-30.8$ & $48.5-43.9$ & $31.0-24.3$ & $32.6-26.1$ & $54.6-49.9$ \\
\hline Test site layout (m) & $90 \times 240$ & $90 \times 240$ & $90 \times 240$ & $120 \times 480$ & $120 \times 480$ & $120 \times 480$ & $120 \times 480$ & $120 \times 480$ & $120 \times 480$ \\
\hline Solar zenith & 27.4 & 24.6 & 27.0 & 24.8 & 28.0 & 45.3 & 24.9 & 26.1 & 50.4 \\
\hline Solar azimuth & 130.6 & 121.6 & 122.8 & 120.8 & 123.6 & 143.8 & 120.6 & 121.3 & 146.0 \\
\hline View zenith & 1.6 & 1.4 & 1.5 & 1.3 & 0.3 & 1.4 & 1.3 & 1.3 & 0.1 \\
\hline View azimuth & 98.2 & 98.2 & 98.2 & 98.2 & 103.0 & 98.2 & 98.2 & 98.2 & 105.0 \\
\hline Temperature $\left({ }^{\circ} \mathrm{C}\right)$ & 32 & 13 & 30 & 34 & 39 & 19 & 30 & 33 & 13 \\
\hline Pressure (mb) & 858 & 855 & 851 & 856 & 859 & 859 & 857 & 854 & 860 \\
\hline Angstrom parameter & 1.16 & 1.68 & 0.35 & 1.12 & 1.42 & 0.90 & 2.18 & 1.03 & 0.66 \\
\hline Water vapor (cm) & 1.36 & 0.53 & 0.77 & 0.56 & 2.48 & 0.76 & 1.47 & 1.71 & 0.91 \\
\hline $\begin{array}{l}\text { Aerosol optical depth } \\
\text { @ } 550 \mathrm{~nm}\end{array}$ & 0.073 & 0.032 & 0.040 & 0.110 & 0.097 & 0.075 & 0.095 & 0.089 & 0.038 \\
\hline Ozone (DU) & 308 & 311 & 328 & 303 & 280 & 313 & 296 & 299 & 308 \\
\hline
\end{tabular}


Table II. Summary of ROLO model-based comparison to Hyperion with associated reflectance-based results.

\begin{tabular}{|c|c|c|c|c|c|c|c|}
\hline \multirow{2}{*}{$\begin{array}{l}\text { Hyperion } \\
\text { channel }\end{array}$} & \multirow{2}{*}{$\begin{array}{l}\text { Band } \\
\text { center }\end{array}$} & \multicolumn{2}{|c|}{$\begin{array}{l}\text { Mean percent difference from Hyperion } \\
\text { radiance }\end{array}$} & \multicolumn{2}{|c|}{$\begin{array}{c}\text { Percent standard } \\
\text { deviation }\end{array}$} & \multicolumn{2}{|c|}{$\%$ change/year } \\
\hline & & Refl-based & ROLO-based & $\begin{array}{l}\text { Refl- } \\
\text { based }\end{array}$ & $\begin{array}{c}\text { ROLO- } \\
\text { based }\end{array}$ & $\begin{array}{l}\text { Refl- } \\
\text { based }\end{array}$ & $\begin{array}{c}\text { ROLO- } \\
\text { based }\end{array}$ \\
\hline 11 & 457 & 12.15 & -3.87 & 1.60 & 0.90 & -0.37 & -0.28 \\
\hline 25 & 599 & -2.15 & 13.39 & 1.87 & 0.52 & -0.77 & -0.04 \\
\hline 45 & 803 & 1.64 & 8.43 & 1.98 & 0.57 & -0.73 & -0.09 \\
\hline 106 & 1205 & 2.54 & -1.23 & 2.21 & 0.59 & -0.36 & -0.02 \\
\hline 135 & 1497 & -3.56 & -1.75 & 4.60 & 0.63 & -2.36 & 0.01 \\
\hline 210 & 2254 & 5.33 & 2.08 & 1.27 & 0.65 & -0.14 & -0.04 \\
\hline
\end{tabular}


Joel McCorkel received a BS degree in Optical Engineering and $\mathrm{PhD}$ in Optical Sciences from the University of Arizona. He joined the National Ecological Observatory Network as a staff scientist for the Airborne Observation Platform in 2009. $\mathrm{He}$ is currently a physical scientist in the Biospheric Sciences Laboratory at NASA's Goddard Space Flight Center, Greenbelt, Maryland.

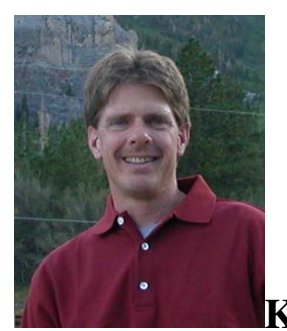

Kurt Thome obtained a BS degree in meteorology from Texas A\&M University and MS and PhD degrees in atmospheric sciences from the University of Arizona. He then joined what is now the College of Optical Sciences becoming full professor in 2006. He served as the Director of the Remote Sensing Group from 1997 to 2008. Thome moved to NASA's Goddard Space Flight Center in 2008 as a Physical Scientist in the Biospheric Sciences Laboratory. He has been a member of the Landsat-7, ASTER, MODIS, and EO-1 Science Teams providing vicarious calibration results for those and other imaging sensors. He is a Fellow of SPIE, is the Instrument Scientist for the Visible Infrared Imaging Radiometer Suite on the Joint Polar Satellite System and is serving as the calibration lead for the Thermal Infrared Sensor on the Landsat Data Continuity Mission. Thome is the Deputy Project Scientist for CLARREO for which he is also the instrument lead for the Reflected Solar Instrument.

\section{Lawrence Ong}

